\title{
A statistical analysis of sounding derived indices and parameters for extreme and non-extreme thunderstorm events over Cyprus
}

\author{
K. Savvidou ${ }^{1}$, A. Orphanou ${ }^{1}$, D. Charalambous ${ }^{1,2}$, P. Lingis ${ }^{1}$, and S. Michaelides ${ }^{1}$ \\ ${ }^{1}$ Cyprus Meteorological Service, Nicosia, 1418, Cyprus \\ ${ }^{2}$ Department of Physics, University of Lancaster, Lancaster, LA1 4YB, UK
}

Received: 11 March 2009 - Revised: 16 June 2010 - Accepted: 19 June 2010 - Published: 25 June 2010

\begin{abstract}
The main purpose of this study is to provide a simple statistical analysis of several stability indices and parameters for extreme and non-extreme thunderstorm events during the period 1997 to 2001 in Cyprus. For this study, radiosonde data from Athalassa station $\left(35^{\circ} 1^{\prime} \mathrm{N}, 33^{\circ} 4^{\prime} \mathrm{E}\right)$ were analyzed during the aforementioned period. The stability indices and parameters set under study are the $\mathrm{K}$ index, the Total Totals (TT) index, the Convective Available Potential Energy related parameters such as Convective Available Potential Energy (CAPE), Downdraft CAPE (DCAPE) and the Convective Inhibition (CIN), the Vorticity Generator Parameter (VGP), the Bulk Richardson Number (BRN), the BRN Shear and the Storm Relative Helicity (SRH). An event is categorized as extreme, if primarily, CAPE was non zero and secondary, if values of both the K and the TotalTotals (TT) indices exceeded 26.9 and 50, respectively. The cases with positive CAPE but lower values of the other indices, were identified as non-extreme. By calculating the median, the lower and upper limits, as well as the lower and upper quartiles of the values of these indices, the main characteristics of their distribution were determined.
\end{abstract}

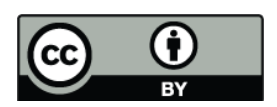

Correspondence to: K. Savvidou (lefele@cytanet.com.cy)

\section{Introduction}

Stability indices have been developed and used for both research and operational forecasting of severe weather and thunderstorms by quantifying the thermodynamic instability with the aid of radiosonde data. In general, it should be noted that all the stability indices describe the potential for convection, but the thresholds may vary with geographical location, season and synoptic situation. This paper is dealing with the statistical analysis of 9 parameters and/or indices in the area of Cyprus; the CAPE, DCAPE, CIN, BRN, SRH, VGP, BRNsh, TT and $\mathrm{K}$ index. In forecasting the most severe convective storms, which also tend to be those that are longlasting and rotating, parameters such as the Bulk Richardson Number (Weisman and Klemp, 1982), BRN shear (Rasmussen and Wilhelmson, 1983) and storm-relative helicity SRH (Davies-Jones, 1984) have been used. These parameters gained acceptance in practical applications through theoretical, numerical modeling and observational studies. The definition and interpretation of the various indices can also be found online (National Weather Service, 2010) and in König (2002). The present analysis aims to determine the ranges of values of the aforementioned indices for the occurrence of extreme and non extreme weather events.

\section{Methodology}

From a 5-year period thermodynamic indices and parameters data base, the dates with a non zero CAPE were selected. For these dates the atmosphere had the potential to give extreme or non-extreme thunderstorm events. From

Published by Copernicus Publications on behalf of the European Geosciences Union. 

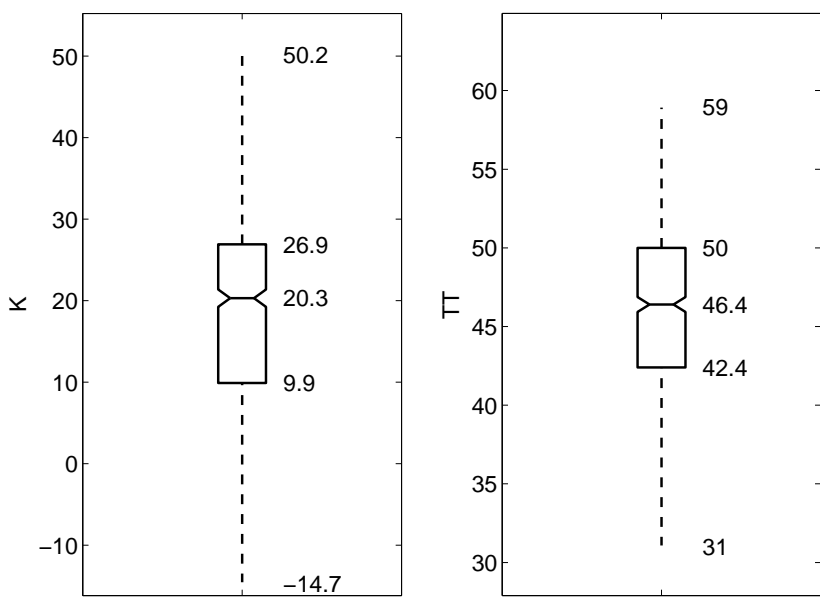

Fig. 1. The distribution of the values of the $\mathrm{K}$ and TT indices of all cases with non-zero value of CAPE.

the aforementioned dates, in order to have more realistic results, a second selection was made; only the dates for which the values of all the thermodynamic indices and parameters were available were set under further study. For these cases, the median, the lower and the upper quartile of the $\mathrm{K}$ and TT indices were calculated and their distribution was presented graphically using a "box-and-whisker" plot. The latter provides a convenient, graphical way to display the smallest value, lower quartile, median, upper quartile and largest value of a set of data. From this analysis the cases which were above the upper quartiles, were selected and classified as potentially extreme weather cases, 69 in number. The statistical analysis, using the box and whisker method, of the CAPE, DCAPE, CIN, BRN, SRH, VGP and BRNsh was performed for both categories, extreme and nonextreme weather cases. A second selection was carried out and 44 days, where extreme weather events were observed, according to the monthly report of the Meteorological Service of Cyprus, were selected. The number of observed extreme weather cases was much larger, but only the cases where all indices values were available were set under study. For these two groups of days, the ones that the potential index and/or parameter values suggested to be associated with extreme weather and the ones that extreme weather actually occurred, the mean values of the aforementioned indices and/or parameters were studied (see Table 1).

\section{Results}

\section{1 $\mathrm{K}$ and TT indices}

Figure 1 shows the statistical distribution of all the non-zero CAPE soundings. $75 \%$ of the soundings have $\mathrm{K}$ index values below 26.9 and TT index values below 50 . These two values were used for the definition of an extreme event, i.e. one
Table 1. Average index values for the potentially and observed extreme weather cases.

\begin{tabular}{lrr}
\hline Index & Potential & Observed \\
\hline $\mathrm{K}\left({ }^{\circ} \mathrm{C}\right)$ & 31.5 & 24.0 \\
$\mathrm{TT}\left({ }^{\circ} \mathrm{C}\right)$ & 54.0 & 50.3 \\
$\mathrm{CAPE}\left(\mathrm{J} \mathrm{kg}^{-1}\right)$ & 961.2 & 512.4 \\
$\mathrm{CIN}\left(\mathrm{J} \mathrm{kg}^{-1}\right)$ & 26.1 & 24.9 \\
$\mathrm{BRN}$ & 77.1 & 28.3 \\
$\mathrm{VGP}\left(\mathrm{J} \mathrm{kg}^{-1}\right)$ & 0.2 & 0.2 \\
$\mathrm{SRH}\left(\mathrm{J} \mathrm{kg}^{-1}\right)$ & 74.0 & 64.2 \\
BRNsh $\left(\mathrm{J} \mathrm{kg}^{-1}\right)$ & 43.3 & 47.3 \\
DCAPE $\left(\mathrm{J} \mathrm{kg}^{-1}\right)$ & 654.6 & 263.6 \\
\hline
\end{tabular}

Table 2. Mean seasonal index values for the potentially $(\mathrm{P})$ and observed $(\mathrm{O})$ extreme weather cases.

\begin{tabular}{lrrrrrrrr}
\hline & \multicolumn{2}{c}{ Winter } & \multicolumn{2}{c}{ Spring } & \multicolumn{2}{c}{ Summer } & \multicolumn{2}{c}{ Autumn } \\
\hline & $\mathrm{P}$ & $\mathrm{O}$ & $\mathrm{P}$ & $\mathrm{O}$ & $\mathrm{P}$ & $\mathrm{O}$ & $\mathrm{P}$ & $\mathrm{O}$ \\
\hline K & 28.7 & 21.6 & 30.0 & 22.5 & 36.2 & 34.3 & 30.6 & 28.5 \\
TT & 52.0 & 49.8 & 53.0 & 51.9 & 59.1 & 51.6 & 51.9 & 49.7 \\
CAPE & 346.8 & 391.8 & 702.7 & 580.5 & 1648.8 & 1678.0 & 1004.1 & 553.8 \\
CIN & 27.1 & 12.7 & 13.5 & 2.3 & 25.9 & 57.0 & 38.4 & 63.3 \\
BRN & 39.3 & 24.5 & 24.6 & 27.2 & 168.9 & 169.0 & 74.4 & 23.8 \\
VGP & 0.1 & 0.1 & 0.2 & 0.2 & 0.3 & 0.327 & 0.2 & 0.2 \\
SRH & 84.3 & 75.9 & 94.9 & 44.2 & 52.2 & 13.0 & 65.6 & 67.4 \\
BRNsh & 46.2 & 45.4 & 59.3 & 42.4 & 29.9 & 10.0 & 37.0 & 58.3 \\
DCAPE & 166.1 & 115.5 & 488.7 & 227.3 & 1217.0 & 1266 & 635.6 & 460.2 \\
\hline
\end{tabular}

having $\mathrm{K}$ and TT values higher than the above thresholds, all other non-zero CAPE events being categorized as nonextreme.

\subsubsection{K index}

This index is due to George (1960) and is defined by

$\mathrm{K}=\left(T_{850}-T_{500}\right)+D_{850}-\left(T_{700}-D_{700}\right)$

Here, $T_{i}$ and $D_{i}$ denote the temperature and dew point temperature at a height corresponding to $(i) \mathrm{hPa}$. The $\mathrm{K}$ index is a measure of the thunderstorm potential based on vertical temperature lapse rate, moisture content of the lower atmosphere, and the vertical extent of the moist layer. For the days with observed extreme weather, the upper quartile was not reached, on an annual base; it was limited within the median and the upper quartile. Nevertheless, it seems to be indicative during summer and autumn, while in winter and spring period lower values of around $22^{\circ} \mathrm{C}$, should alert for possible extreme weather (Table 2). 


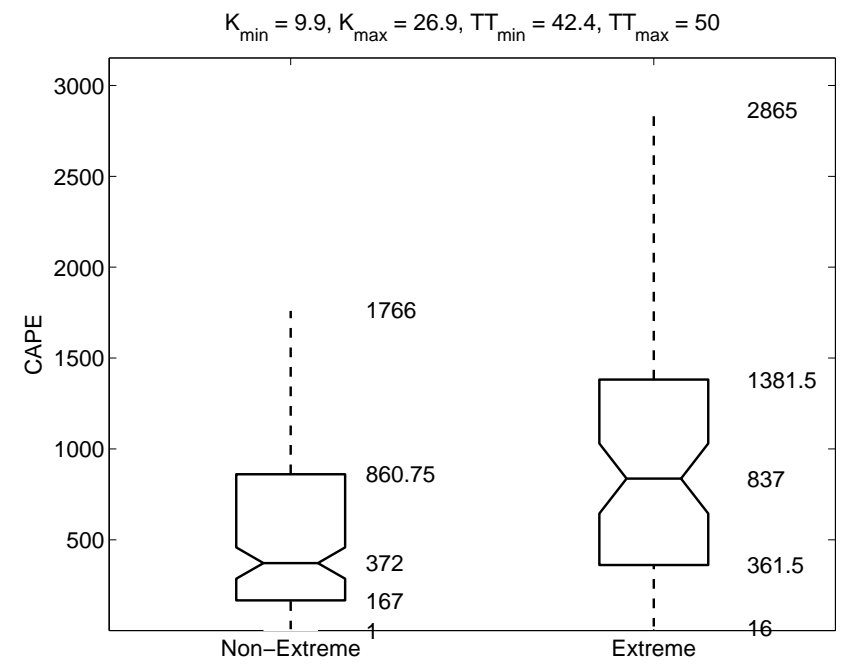

Fig. 2. The distribution of the values of the CAPE index for the days where extreme (right) and non-extreme (left) events occurred.

\subsubsection{Total Totals index}

Totals Indices: The Total Totals index is attributable to Miller (1972). It is defined as the sum of two indices:

$\mathrm{TT}=\mathrm{VT}+\mathrm{CT}$

where VT is the Vertical Totals index, defined by $\mathrm{VT}=T_{850}-T_{500}$, and the Cross Totals index, CT, defined by $\mathrm{CT}=D_{850}-T_{500}$. During the observed extreme cases the upper quartile is overreached in spring and summer and in autumn and winter had slightly lower TT values, of almost $50{ }^{\circ} \mathrm{C}$ (Table 2).

\subsection{Statistical analysis of the extreme and non extreme weather cases}

\subsubsection{CAPE: Convective Available Potential Energy}

CAPE is the maximum energy available to an ascending parcel and is given by

$\mathrm{CAPE}=\int_{p_{\mathrm{n}}}^{p_{\mathrm{f}}}\left(\alpha_{p}-\alpha_{e}\right) \mathrm{d} p$,

where $p_{\mathrm{n}}$ is the pressure at the level of neutral buoyancy, $p_{\mathrm{f}}$ is the pressure at the level of free convection, $\alpha_{e}$ the specific volume of the environment and $\alpha_{p}$ that of a parcel ascending moist-adiabatically from the level $p_{\mathrm{f}}$. The $75 \%$ of the non extreme cases can occur with CAPE less than $860.8 \mathrm{~J} \mathrm{~kg}^{-1}$, while the $50 \%$ of the extreme cases may occur with CAPE more than $837 \mathrm{~J} \mathrm{~kg}^{-1}$ (see Fig. 2). The upper limit for the non-extreme cases $\left(860.8 \mathrm{~J} \mathrm{~kg}^{-1}\right)$ and the median limit for the extreme ones $\left(837 \mathrm{~J} \mathrm{~kg}^{-1}\right)$ are only overreached in summer and autumn for the potentially extreme days and in summer for the observed ones. In winter CAPE of 350 to

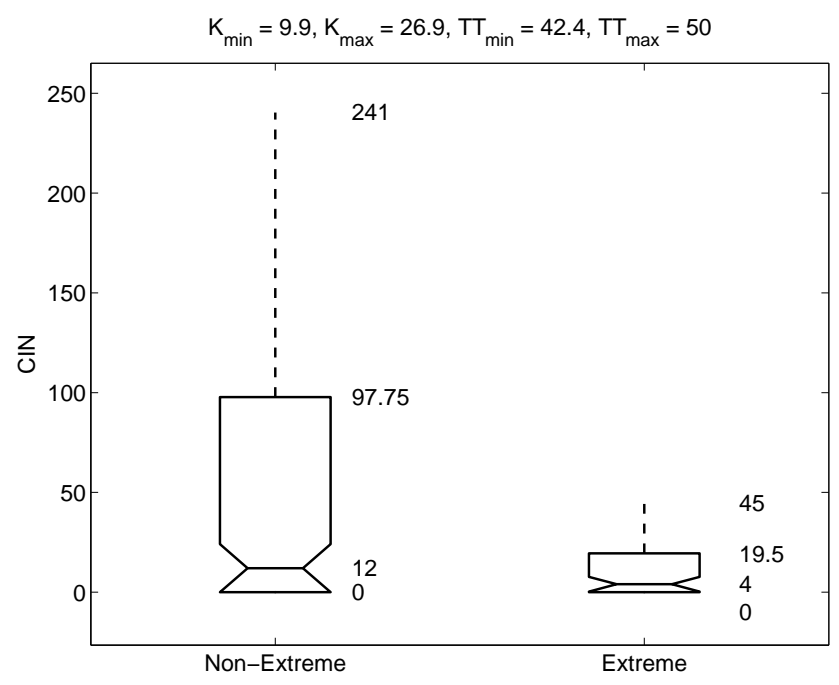

Fig. 3. The distribution of the values of the CIN index for the days where extreme (right) and non-extreme (left) events occurred.

$400 \mathrm{~J} \mathrm{~kg}^{-1}$ may be related to extreme weather occurrence. In spring, extreme weather was observed with CAPE mean values of $580 \mathrm{~J} \mathrm{~kg}^{-1}$. A significant differentiation was noted between the mean seasonal CAPE values of the two studied groups in autumn. Although the potentially extreme cases require CAPE of around $1000 \mathrm{~J} \mathrm{~kg}^{-1}$, the respective mean value of the observed cases was only $553.8 \mathrm{~J} \mathrm{~kg}^{-1}$ (Table 2).

\subsubsection{CIN: Convective Inhibition}

The energy required lifting an air parcel vertically and pseudoadiavadically from its present level $\left(p_{\mathrm{i}}\right)$ to its level of free convection is given by

$\mathrm{CIN}=\int_{p_{\mathrm{i}}}^{p_{\mathrm{f}}} R_{\mathrm{d}}\left(T_{\mathrm{vp}}-T_{\mathrm{ve}}\right) \mathrm{d} \ln p$

The quantities $T_{\mathrm{vp}}$ and $T_{\mathrm{ve}}$ represent the virtual temperature profiles of the parcel and the environment, respectively. From the analysis it has arisen that $75 \%$ of the extreme cases occur with CIN $<19.5 \mathrm{~J} \mathrm{~kg}^{-1}$, while $50 \%$ of the non extreme cases occur with CIN $>12 \mathrm{~J} \mathrm{~kg}^{-1}$ (see Fig. 3). The mean annual values of CIN for potentially and observed extreme cases are around $25 \mathrm{~J} \mathrm{~kg}^{-1}$ (see Table 1). It is worth noticing, though, the seasonal differences of the values on the days with observed extreme weather; in winter and spring, much less energy is required, while in summer and autumn this amount increases to more than $55 \mathrm{~J} \mathrm{~kg}^{-1}$ (Table 2) .

\subsubsection{DCAPE: Downdraft Convective Available Potential Energy}

The maximum energy available to a descending parcel may be expressed as

$\mathrm{DCAPE}=-\int_{p_{\mathrm{f}}}^{p_{\mathrm{s}}}\left(\alpha_{p}-\alpha_{e}\right) \mathrm{d} p$, 


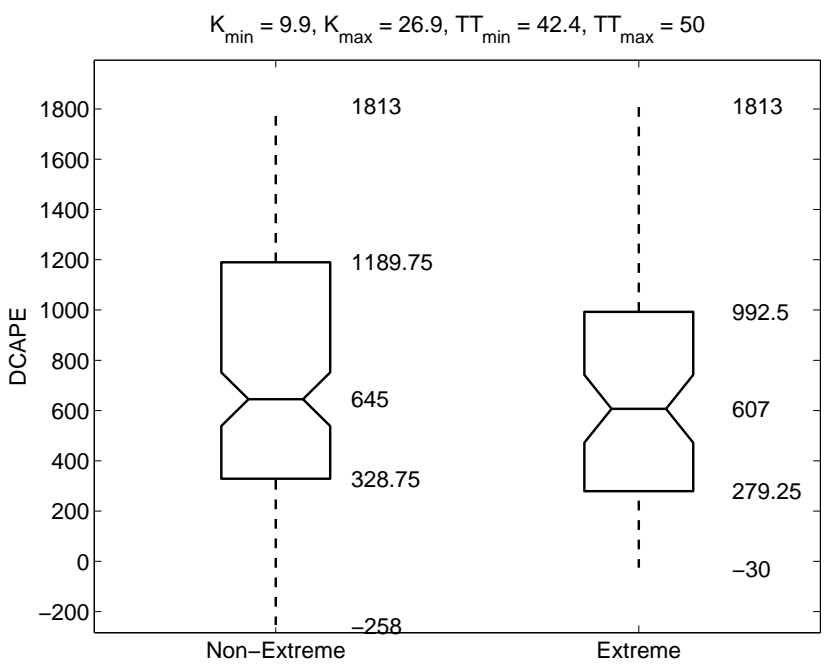

Fig. 4. The distribution of the values of the DCAPE index for the days where extreme (right) and non-extreme (left) events occurred.

where $p_{\mathrm{s}}$ is the surface pressure and $p_{\mathrm{f}}$ in this case denotes the level of free sink. From the DCAPE distribution shown in Fig. 4, no significant discrimination between the extreme and not extreme cases is found. The upper limit for the nonextreme cases $\left(1189.8 \mathrm{~J} \mathrm{~kg}^{-1}\right)$ and the median limit for the extreme ones $\left(607 \mathrm{~J} \mathrm{~kg}^{-1}\right)$ are only overreached in summer and autumn for the potentially extreme cases and in summer for the observed ones (Table 2).

Again, notable seasonal variations are noted; much lower values are associated with observed and potentially extreme weather in winter $\left(115,166 \mathrm{~J} \mathrm{~kg}^{-1}\right)$ and in increasing order, spring $\left(227,489 \mathrm{~J} \mathrm{~kg}^{-1}\right)$, autumn $\left(460,636 \mathrm{~J} \mathrm{~kg}^{-1}\right)$ and summer $\left(1266,1217 \mathrm{~J} \mathrm{~kg}^{-1}\right)$ (Table 2).

\subsubsection{BRN: Bulk Richardson Number}

The BRN is defined as the dimensionless ratio of CAPE to a measure of the vertical wind shear. From the BRN distribution shown in Fig. 5, it can be seen that $75 \%$ of the non extreme cases have BRN values less than 44 and more than $50 \%$ of the extreme cases have values less than 50 , which denote that the environment is favored for supercells (Weisman and Klemp, 1982), meaning that the BRN is a poor predictor. The mean value of the BRN for the observed cases is less than the median, while for the potentially is above the upper quartile. By looking the seasonal values, during winter and spring much lower BRN was noted, for both the potentially and observed extreme days. In summer the BRN is much bigger, around 169 for the two groups of cases. Finally, in autumn the potentially extreme cases exceeded the upper quartile limit, but for the observed ones the BRN was again lower, even lower than the median $($ median $=32)($ Table 2$)$.

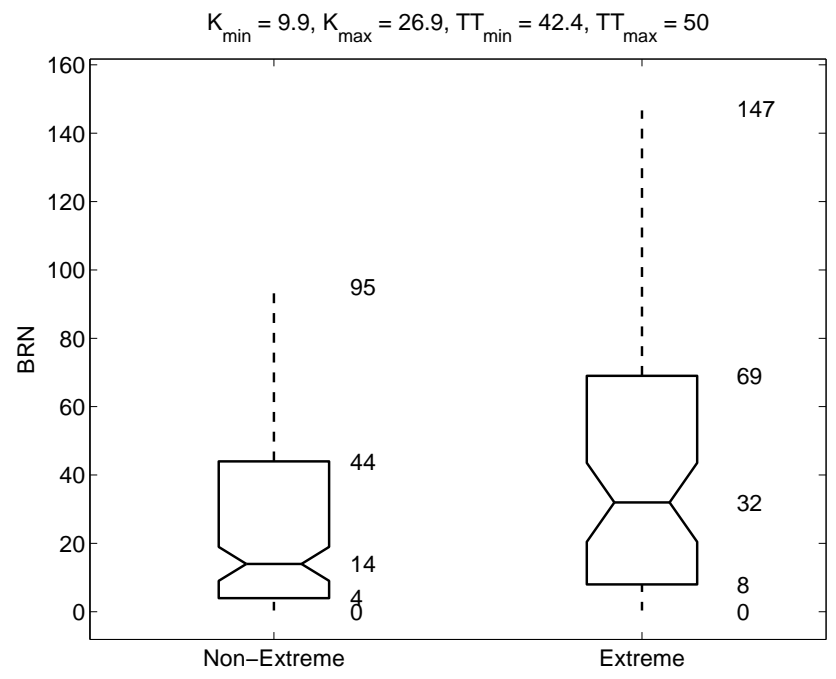

Fig. 5. The distribution of the values of the BRN index for the days where extreme (right) and non-extreme (left) events occurred.

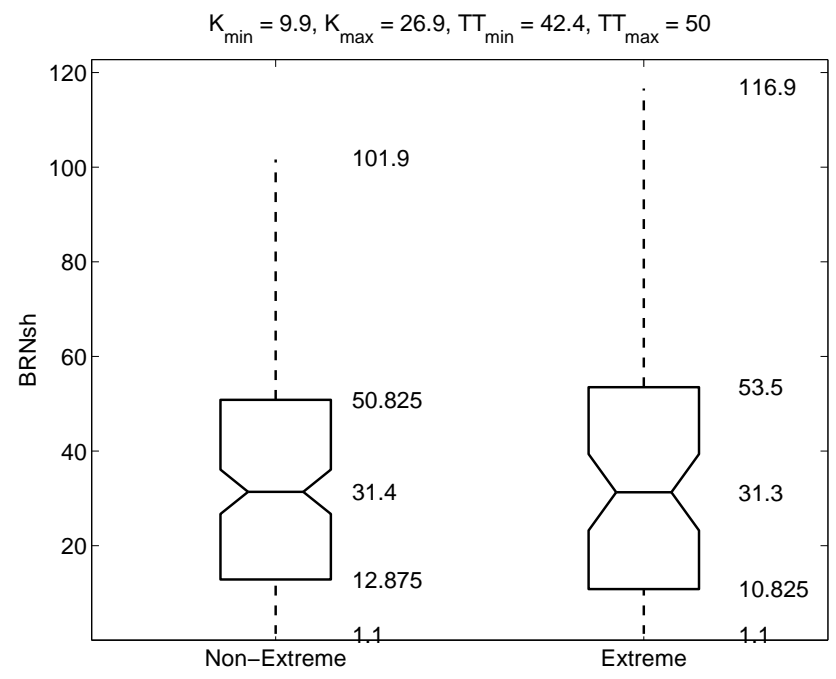

Fig. 6. The distribution of the values of the BRNsh index for the days where extreme (right) and non-extreme (left) events occurred.

\subsubsection{BRNsh}

The BRNsh parameter provides a measure for the vector difference in the wind through the vertical.

The plot of the BRNsh (see Fig. 6) implies that this index is a very poor predictor for the extreme and not extreme cases. The BRNsh index values for the observed extreme cases ranged within the median and the upper quartile limits. The lowest values were found in summer, where observed extreme weather is related to values of $10 \mathrm{~J} \mathrm{~kg}^{-1}$, which is lower than the lower quartile limit (Table 2). 


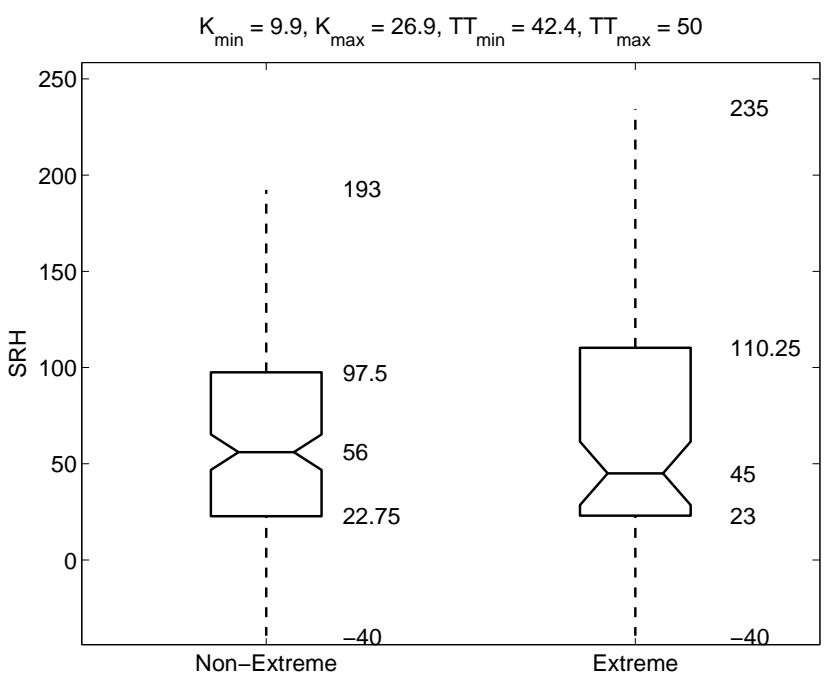

Fig. 7. The distribution of the values of the SRH index for the days where extreme (right) and non-extreme (left) events occurred.

\subsubsection{SRH: Storm Relative Helicity}

SRH (Davies-Jones et al., 1990) provides a measure of any tornado potential and is defined as

$\mathrm{SRH}=-\int_{0}^{h} \boldsymbol{k} \cdot(\boldsymbol{V}-\boldsymbol{c}) \times \frac{\partial \boldsymbol{V}}{\partial z} \mathrm{~d} z$

where $\boldsymbol{V}$ is the horizontal velocity vector, $\boldsymbol{c}$ is the storm motion vector and $h$ is the storm depth. As can be concluded from the plot (see Fig. 7), the SRH is a very poor predictor.

The SRH index values, for the potentially and observed extreme cases, ranged within the median and the upper quartile limits (45-110.3 $\left.\mathrm{J} \mathrm{kg}^{-1}\right)$; higher values were found for winter, spring and autumn. In winter and spring the days with observed extreme weather had lower SRH values compared with the potentially ones, while slightly higher values were noted in autumn. In summer, the mean SRH value on the days with observed extreme weather was only $13.0 \mathrm{~J} \mathrm{~kg}^{-1}$, which is even lower than the lower quartile limit $\left(23 \mathrm{~J} \mathrm{~kg}^{-1}\right)$ (Table 2).

\subsubsection{VGP: Vorticity Generator Parameter}

VGP provides a measure for the probability of vorticity being tilted into the vertical, leading to rotating updrafts; this is defined by (Rasmussen \& Wilhelmson, 1983):

$\mathrm{VGP}=\bar{s} \sqrt{\mathrm{CAPE}}$

where $\bar{s}$ is the mean shear (or hodograph length divided by depth), given by

$\bar{s}=\frac{1}{h} \int_{0}^{h} \frac{\partial V}{\partial z} \mathrm{~d} z$

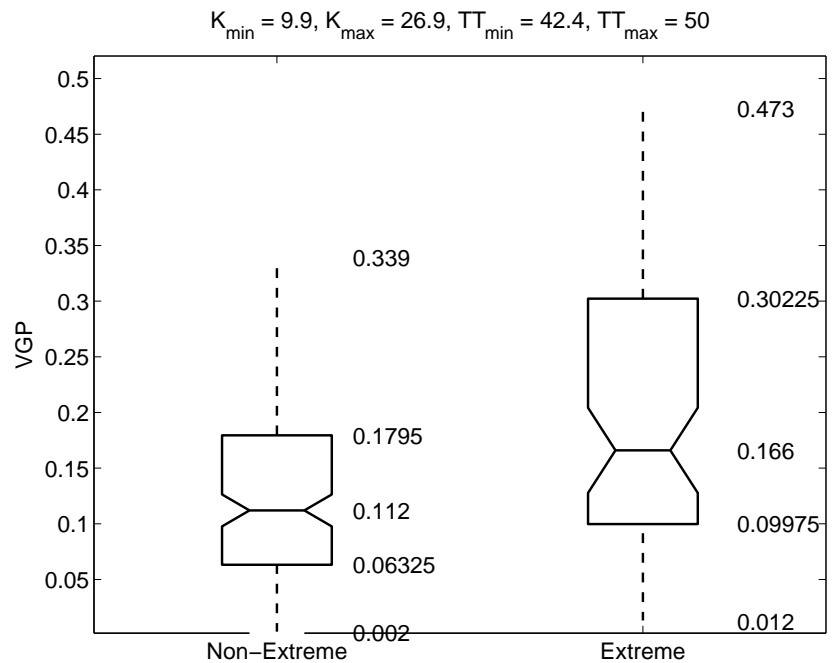

Fig. 8. The distribution of the values of the VGP index for the days where extreme (right) and non-extreme (left) events occurred.

From the VGP plot (see Fig. 8), it can be concluded that the VGP index is a better predictor between the two groups than the DCAPE, SRH and BRNsh. $75 \%$ of the non extreme cases have values below $0.18 \mathrm{~J} \mathrm{~kg}^{-1}$, while $50 \%$ of the extreme cases have values above $0.17 \mathrm{~J} \mathrm{~kg}^{-1}$. From the study of VGP for the potentially and observed extreme cases it has also arisen that the upper quartile limit for the extreme cases $\left(0.302 \mathrm{~J} \mathrm{~kg}^{-1}\right)$ is only representative in summer. Values of 0.2 can be regarded as adequate for extreme weather to occur in spring and autumn, while in winter even 0.1 should alert for extreme weather (Table 2).

\subsection{Comparison of the frequency of occurrence of the potentially and observed extreme weather days}

As mentioned before, the selection of the days considered as potentially extreme weather cases, was based on the criteria set using the $\mathrm{K}$ and TT indices. For the criteria and thresholds to be adopted, the number of the potential cases should be similar to the observed ones. In other case, the thresholds should be modified. The 69 extreme weather cases as defined by the upper quartiles of the TT and $\mathrm{K}$ indices are seasonally distributed as follows (see Figs. 9 and 10 for the seasonal and monthly distribution, respectively); 12 in winter (DJF), 20 in spring (MAM), 17 in summer (JJA) and 20 in autumn (SON), with higher frequencies of occurrence during June (12), May (9) and October (8).

The 44 observed extreme weather cases are seasonally distributed as follows; 20 in winter (DJF), 11 in spring (MAM), 1 in summer (JJA) and 12 in autumn (SON), with higher frequencies occurring in December (14), October (6) and March (5). By looking at the seasonal distribution of the cases (Fig. 9), it is evident that the thresholds TT $=50$ and $\mathrm{K}=26.9$ can be considered as satisfactory for the spring and 


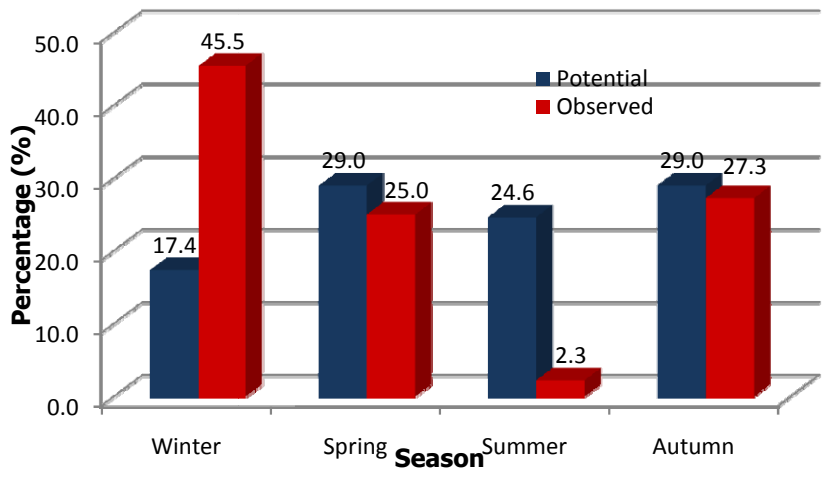

Fig. 9. Seasonal distribution of the potentially and observed extreme weather cases.

autumnal season, since the percentage of occurrence is similar for the two studied groups. On the contrary, these thresholds cannot be regarded as indicative for winter; they exclude a significant number of extreme weather cases during wintertime. For this reason, when the applications refer to the area of Cyprus during the winter period, these thresholds should be modified, by lowering the threshold points. Unfortunately, no trustworthy results can be derived for the summer season; only one case of extreme weather was reported in August (a number of cases was excluded due to missing radiosonde data) and the increased False Alarm Rate suggested by the percentage difference between the potential and the observed group may be misleading.

\section{Conclusions}

The primary aim of this study is to provide a useful tool for distinguishing extreme and non-extreme thunderstorm events over Cyprus. The thresholds used for assessing and categorizing weather events are set using the upper quartile of the distribution of the $\mathrm{K}$ and TT indices corresponding to non-zero CAPE. The analysis has shown that out of the seven indices studied, only two of them can be considered as good predictors: these are the CAPE and VGP indices. The median of the extreme is almost the same with the upper quartile of the non-extreme events leading to the conclusion that soundings with CAPE above $837 \mathrm{~J} \mathrm{~kg}^{-1}$ and VGP above $0.17 \mathrm{~J} \mathrm{~kg}^{-1}$ will have the potential for extreme thunderstorm events. The analysis based on the mean values of the same indices and/or parameters of the potentially extreme events and the observed ones reveals the following:

1. The mean values of the CAPE-related parameters and the shear-CAPE combination parameters for both groups exhibit their maximum values during the summer and their lowest values mainly during winter. There are two plausible reasons for this distribution; the tropopause is higher during the summer and the shear

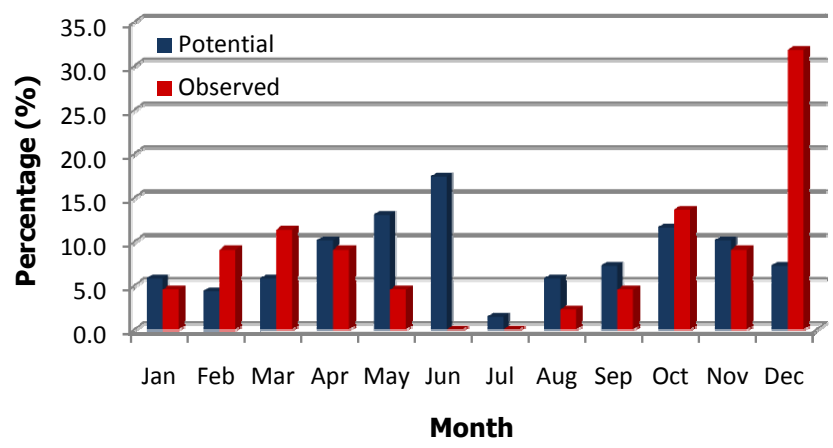

Fig. 10. Monthly distribution of the potentially and observed extreme weather cases.

is weak. The occurrence of thunderstorm events during winter with low CAPE values are strongly related to dynamics effects i.e. baroclinic depressions.

2. The mean values of the shear-related parameters display their maximum values during spring and their lowest during the summer.

3. For the same indices stated in 1 above (except the VGP index) the mean values of the potentially-extreme events are higher than the observed ones during spring and autumn. This is because the thunderstorm events are also related to dynamic effects. The seasonal mean value of VGP is the same for both the potentially-extreme and the observed extreme cases.

The percentage of occurrence of the potentially-extreme and the observed-extreme thunderstorm events are similar during spring and autumn. During winter the number of the observed-extreme events is higher than that of the potentially-extreme events and this can be attributed partly to the dynamic effects that can lead to extreme thunderstorm events.

Acknowledgements. This study was undertaken within the framework of Project "FLASH" which is funded by the European Union (Sixth Framework Programme, Contract No. 036852). Also, the authors would like to thank both reviewers for their very useful and constructive comments.

Edited by: K. Nicolaides

Reviewed by: P. T. Nastos and another anonymous referee

\section{References}

Davies-Jones, R. P.: Streamwise vorticity: The origin of updraft rotation in supercell storms, J. Atmos. Sci., 41, 2991-3006, 1984.

Davies-Jones, R. P., Burgess, D., and Foster, M.: Test of helicity as a tornado forecast parameter, Preprints, 16th Conf. on Severe Local Storms, Kananaskis Park, AB, Canada, Am. Meteor. Soc., 588-592, 1990. 
George, J. J.: Weather forecasting for aeronautics, Academic Press, New York, 409-415, 1960.

König, M.: Atmospheric Instability Parameters Derived from MSG SEVIRI Observations, EUMETSAT Technical Memorandum No. 9, 2002.

Miller, R. C.: Notes on analysis and severe-storm forecasting procedures of the Air Force Global Weather Central, AWS Tech. Rpt. 200(rev), Air Weather Service, Scott AFB, IL, 1972.
National Weather Service web site: http://www.crh.noaa.gov/lmk/ soo/docu/indices.php, last access: 16 June, 2010.

Rasmussen, E. N. and Wilhelmson, R. B.: Relationships between storm characteristics and 100 GMT hodographs, low-level shear and instability. Preprin, 13th Conf. on Severe Local Storms, Tulsa, OK, Am. Meteor. Soc., J5-J8, 1983.

Weisman, M. L. and Klemp, J. B.: The dependence of numerically simulated convective storms on vertical wind shear and buoyancy, Mon. Weather Rev., 110, 504-520, 1982. 